\title{
BIRTH ASPHYXIA; SHORTTERM OUTCOME OF NEONATES TREATED WITH ALLOPURINOL
}

1. MBBS, DCH, FCPS

Associate Professor of Pediatrics Quaid e Azam Medical College, Bahawalpur.

2. MBBS, FCPS

Associate Professor of Pediatrics Shaikh Zayed Medical College, Rahim Yar Khan

3. MBBS, MCPS, FCPS

Assistant Professor Gynae \& Obst. Quaid e Azam Medical College Bahawalpur.

4. MBBS, DCH, FCPS

Assistant Professor Pediatrics Quaid e Azam Medical College, Bahawalpur.

5. MBBS, MCPS

Post Graduate Registrar

Pediatrics Unit-2,

Bahawal Victoria Hospital,

Bahawalpur.

Correspondence Address:

Dr. Muhammad Amin

Associate Professor of Pediatrics

Quaid e Azam Medical College,

Bahawalpur.

dr.aminshbwp@gmail.com

Article received on:

18/03/2017

Accepted for publication:

10/05/2017

Received after proof reading: 05/06/2017
Muhammad Amin', Muhammad Saleem², Shamas-un-Nisa ${ }^{3}$, Malik Muhammad Naeem ${ }^{4}$, Hafiz Muhammad Anwar-ul-Haq ${ }^{5}$

ABSTRACT... Introduction: Out of 130 million births, about four million infants die in the first four weeks of their life. Birth asphyxia is a major cause of neonatal deaths in developing countries. Birth asphyxia is estimated to account for approximately $25 \%$ of neonatal mortality worldwide. Allopurinol is a cheap and freely available medicine whereas other management options are not widely used. Objectives: To analyze the short-term outcome between allopurinol-treated and non-allopurinol-treated asphyxiated neonates. Study Design: A randomized controlled study. Setting: Pediatric unit 2, Bahawal Victoria Hospital, Bahawalpur. Duration of Study: This study was conducted from March 2015 to September 2015. Materials and Methods: A total of 62 (31 in allopurinol and 31 in non allopurinon treated group) infants having admitted within 6 hours after birth with gestational age $\geq 36$ weeks. All were suffering from stage-2 hypoxic ischemic encephalopathy, lethargy, hypotonia, flexion posture. All were having hyperactive tendon reflexes and poor moro reflex. All the admitted neonates were managed and followed up to to 7 days of admission to note the need of anti-convulsants, conscious level and length of admission in intensive care unit ( $\leq 7$ days or $>7$ days). Neonates who died during the stay were noted and compared between both the groups. Results: Out of 62 infants, there were 34 (54.8\%) males and 28 (45.2\%) females. Mean gestational age was 37.90 weeks while mean weight of newborn infants was $2.75 \mathrm{~kg}$. Overall Mortality was noted in $6(9.68 \%)$ infants. When both groups were compared, no statistically significant difference was found between the two groups in terms of sex, gestational age, birth weight or mortality ( $p$ value $>0.05$ ). Conclusion: Short-term outcome in terms of mortality between allopurinol-treated and conventional treatment asphyxiated neonates was found to be 6.5 vs $12.9 \%$.

Key words: Birth asphyxia, cerebral palsy, neuro-developmental delay, allopurinol, mortality.

Article Citation: Amin M, Saleem M, Shamas-un-Nisa, Naeem MM, Anwar-ul-Haq HM. Birth asphyxia; short-term outcome of neonates treated with allopurinol. Professional Med J 2017;24(6):796-800. DOI: 10.17957/TPMJ/17.3931

\section{INTRODUCTION}

Birth Asphyxia is the inability of the newborn to initiate and sustain adequate respiration after delivery. ${ }^{1}$ Birth asphyxia is responsible for approximately $25 \%$ of neonatal mortality around the world. ${ }^{2,3}$ About 4 to 9 million newborns face birth asphyxia every year. ${ }^{4}$ Birth asphyxia proves fatal for 1.2 million newborns annually and same number develop major complications like cerebral palsy, epilepsy and neuro-developmental delay. ${ }^{4}$

In Pakistan, nearly $65 \%$ of neonatal mortality is secondary to birth asphyxia which accounts for nearly 80000 deaths annually. ${ }^{5,6}$ Birth asphyxia was responsible for $35 \%$ of deaths in Lahore, $11 \%$ in KPK and $14 \%$ in Karachi while in urban population, $26 \%$ deaths are noted be due to intrapartum asphyxia. ${ }^{7,8}$

Supportive care to maintain appropriate temperature, perfusion, ventilation and normal metabolic state forms the pillar for management of neonatal asphyxia.5,9 For minimizing the complications, early detection by clinical and biochemical assessments plays an important role. $^{9}$

Different management options are considered globally for successful management of neonatal asphyxia but hypothermia remains the only neuroprotective treatment to have been clinically tested in large randomized controlled trials that 
has shown reduction in brain injury in asphyxiated term newborns. ${ }^{10,11}$ Being an Xanthine oxidase inhibitor, allopurinol is known to decrease free radical formation and lipid peroxidation after severe birth asphyxia in newborn. ${ }^{12}$

Allopurinol is a cheap and freely available medicine whereas other management options have not been widely tried and considered costly. Allopurinol seems efficient at reducing mortality ${ }^{13}$ (18\% died with allopurinol vs. 55\% controls) and morbidity ${ }^{14}$ ( $27 \%$ with allopurinol vs. $55 \%$ controls) in neonates with perinatal asphyxia. ${ }^{13}$ Beneficial effect of allopurinol treatment are on free radical formation, Cerebral blood volume (CBV), and electrical brain activity, and all these without toxic side effects. ${ }^{13}$ In previous studies intravenous (I.V) allopurinol was used, but in Pakistan, I.V formulation of allopurinol is not available. Oral formulation of allopurinol was used in this study through nasogastric tube and differences in short-term outcome between asphyxiated neonates on allopurinol treatment and neonates on conventional treatment will be analyzed. The results of this study are aimed to investigate allopurinol as an alternate strategy to treat infants with birth asphyxia as other recommended therapies like induced hypothermia are either not available or very costly.

\section{MATERIAL \&METHODS}

This was a randomized controlled study, conducted in the Department of Paediatrics, Bahawal Victoria Hospital, Bahawalpur from March 2015 to September 2015. Protocol of the study was approved by the Institutional Ethical Committee. The sample size calculated was 62 (31 in each group) neonates with gestational age $\geq 36$ weeks, determined by maternal dates and Ballard score, admission within 6 hours after birth and suffering from stage-2 hypoxic ischemic encephalopathy defined ${ }^{15}$ as neonate having respiratory distress (respiratory rate > 60 breath per minute), lethargy (sluggishness, inactivity), flexion posture (folding of arms and legs), hyperactive tendon reflexes (exaggerated response while performing tendon reflex or clonus), multifocal seizures and poor moro reflex (sluggish response to loss of support). Neonates with congenital or syndromal malformations, delivered at home and who remain admitted in other hospitals for 48 hours, were excluded.

After explaining details and benefits / risks of the study, informed consent was taken from the parents / guardian. Variables recorded for each case included date, registration number, contact number, address, name, father's name, gender and gestational age at the time of admission. Randomization was done by opening numbered sealed envelopes containing cards indicating whether allopurinol treatment was performed or not. Oral allopurinol $40 \mathrm{mg} / \mathrm{kg}$ per day, divided 12 hourly along with available symptomatic treatment was given to allopurinol group whereas conventional treatment group was offered only the available symptomatic treatment. General physical examination included vitals, anthropometric data and all systemic examination. Investigations included: complete blood count $(\mathrm{CBC})$, serum glucose, serum calcium, renal function tests and x-ray chest. All the admitted neonates were managed and followed up to to 7 days of admission. Neonates who died during the stay were noted in both groups. All the data was entered on a pre-designed Performa for each patient (copy attached).

The collected data was analyzed by SPSS version 10. Quantitative variables like gestational age and weight were calculated by mean and standard deviation. Frequency and percentage were calculated for qualitative variables like deaths during the stay. Effect modifiers were controlled by stratification of gestational age, gender and weight. Chi square test was applied to compare the both groups and $p$ value $\leq 0.05$ was taken as statistically significant.

\section{RESULTS}

Out of 62 infants, there were 34 (54.8\%) males and 28 (45.2\%) females. Mean gestational age was found to be 37.90 weeks with standard deviation of 2.03. Mean weight of infants was $2.75 \mathrm{~kg}$ with standard deviation of 0.19 . Overall Mortality was noted in 6 (9.68\%) infants. (Figure-1) 
In Group A, there were 19 (61.3\%) males and $12(38.7 \%)$ females as compared to $15(48.4 \%)$ males and $16(51.6 \%)$ females in Group B with statistically insignificant $p$ value of 0.307 . (Table-I)

In Group A, there were 22 (71.0\%) infants who were delivered with gestational age of $\leq 38$ weeks and $9(29.0 \%)$ with $>38$ weeks as compared to $20(64.5 \%)$ with $\leq 38$ weeks and 11 (35.5\%) having > 38 weeks in Group B with statistically insignificant $p$ value of 0.587 . (Table-II)

In Group A, there were 25 (80.6\%) infants with gestational age of $<3 \mathrm{~kg}$ and $6(19.4 \%)$ with $\geq 3$ $\mathrm{kg}$ as compared to $23(74.2 \%)$ with $<3 \mathrm{~kg}$ and 8 $(25.8 \%)$ having $\geq 3 \mathrm{~kg}$ in Group B with statistically insignificant $p$ value of 0.544 . (Table-III)

As far as mortality was concerned, In Group A, there were $2(6.5 \%)$ infants who died as compared to 4 (12.9\%) in Group B with statistically insignificant $p$ value of 0.390 . (Table-IV)

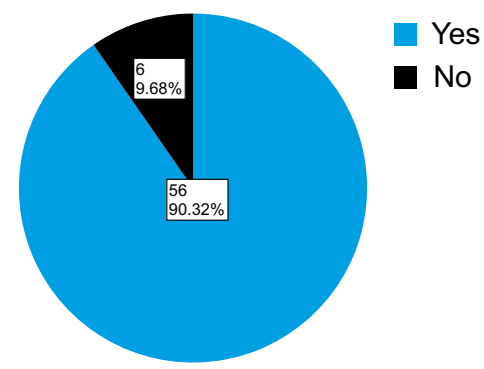

Figure-1. Overall Mortality amongst all the infants

\begin{tabular}{|l|c|c|c|}
\hline \multicolumn{1}{|c|}{ Sex } & \multicolumn{2}{|c|}{ Groups } & Total \\
\hline Male & $19(61.3 \%)$ & $15(48.4 \%)$ & $34(54.8 \%)$ \\
\hline Female & $12(38.7 \%)$ & $16(51.6 \%)$ & $28(45.2 \%)$ \\
\hline Totals & 31 & 31 & 62 \\
\hline \multicolumn{2}{|c|}{$\begin{array}{r}\text { Table-l. Distribution of sex amongst both groups } \\
\text { P value }=0.307\end{array}$} \\
\hline \multicolumn{2}{|c|}{ (statistically insignificant) }
\end{tabular}

\begin{tabular}{|l|c|c|c|}
\hline $\begin{array}{c}\text { Gestational } \\
\text { Age (weeks) }\end{array}$ & A & B & Total \\
\hline$\leq 38$ & $22(71.0 \%)$ & $20(64.5 \%)$ & $42(67.7 \%)$ \\
\hline$>38$ & $9(29.0 \%)$ & $11(35.5 \%)$ & $20(32.3 \%)$ \\
\hline Totals & 31 & 31 & 62 \\
\hline \multicolumn{3}{|c|}{ Pable-Il. Distribution of gestational age amongst both } \\
\hline \multicolumn{3}{|c|}{ Proups } \\
\hline \multicolumn{3}{|c|}{$=0.587$ (statistically insignificant) } \\
\hline
\end{tabular}

\begin{tabular}{|l|c|c|c|}
\hline \multirow{2}{*}{$\begin{array}{c}\text { Birth Weight } \\
(\mathbf{k g})\end{array}$} & \multicolumn{2}{|c|}{ Groups } & Total \\
\hline$<3$ & $25(80.6 \%)$ & $23(74.2 \%)$ & $48(77.4 \%)$ \\
\hline$\geq 3$ & $6(19.4 \%)$ & $8(25.8 \%)$ & $14(22.6 \%)$ \\
\hline Totals & 31 & 31 & 62 \\
\hline
\end{tabular}

Table-III. Distribution of birth weight amongst both groups

$P$ value $=0.544$ (statistically insignificant)

\begin{tabular}{|l|c|c|c|}
\hline \multirow{2}{*}{ Mortality } & A & B & Total \\
\cline { 2 - 4 } & $2(6.5 \%)$ & $4(12.9 \%)$ & $6(9.7 \%)$ \\
\hline Nes & $29(93.5 \%)$ & $27(87.1 \%)$ & $56(90.3 \%)$ \\
\hline Totals & 31 & 31 & 62 \\
\hline \multicolumn{3}{|c|}{ Table-IV. Distribution of mortality amongst both } \\
groups
\end{tabular}

\section{DISCUSSION}

Asphyxia can lead to severe hypoxic ischaemic organ damage in newborns followed by a fatal outcome or severe life-long manifestations. Birth asphyxia is not obvious all the times as the cause of perinatal and postnatal death but its marked influence for the mortality in newborns have been widely noted. ${ }^{16}$

In our findings, there were $34(54.8 \%)$ males and $28(45.2 \%)$ females infants. A local study from Isra University Hospital, Hyderabad found that $60 \%$ of the newborns were male. ${ }^{6}$ In another local study, more male babies (OR 2.3) were having hypoxic ischemic encephalopathy (HIE).${ }^{17}$ Others have also found that male sex is a risk factor for HIE (OR 4.8). ${ }^{18}$ The significance of this finding remains unclear.

Mean gestational age was calculated to be 37.90 weeks. A study conducted in Nepa ${ }^{19}$ found similar numbers as 37.0 weeks. Gestational age of infants did not appear to be a significant risk factor in the present or past findings. ${ }^{17}$ Gestational age of $\geq$ 36 weeks was considered for the current study so premature infants were not taken in this study. Premature infants are always on a risk to ischemic injuries of the white matter. ${ }^{20}$ These newborns are also more prone to have some other potentially fatal problems compared to term infants. 
No prior local study has been done to observe the effect of allopurinol on axphyxiated infants. This was a $1^{\text {st }}$ local study which measured the short term outcome in infants treated with allopurinol. Allopurinol has been a new intervention for birth asphyxiated newborns. Several studies examined allopurinol and reported that its active metabolite oxypurinol offer protection against reperfusion induced brain injury by reducing free radical formation. ${ }^{21}$ The protective action of allopurino is due to its xanthine oxidase-inhibiting property, but at high concentrations, it also scavenges free radicals such as hydroxyl and chelates transition metals like nonprotein-bound iron. ${ }^{22}$

Overall Mortality $9.68 \%$ was noted in this study whereas when both treatment groups were compared $(6.5 \%$ vs $12.9 \%)$, no statistical significance was found in both groups. Allopurinol has been compared previously which showed that allopurinol seemed more effective than placebo at reducing mortality in infants with perinatal asphyxia. Although the difference was not statistically significant, but Van Bel F et $\mathrm{al}^{14}$ noted fewer deaths in infants treated with allopurinol as compared with placebo (36\% vs $64 \%$ ). Another study ${ }^{23}$ found similar mortality in infants using allopurinol as compared to placebo (10\% vs $10 \%)$. A cochrane review ${ }^{24}$ comprising multiple clinical trials found no significant difference between allopurinol and control group. No clear evidence of an effect on mortality, severe disability, neonatal seizure frequency, or the incidence of abnormalities on brain imaging during the neonatal period. As in the current study, more infants seem to survive with allopurinol treatment in asphyxiated newborns but the difference seems to be statistically insignificant as has been observed in the previously conducted trials. There are limited data available that assessed the effect of allopurinol in newborn infants with hypoxic-ischaemic encephalopathy. Previous studies have also not found significant evidence of beneficial effect of allopurinol on mortality, severe disability, neonatal seizure frequency, or brain imaging abnormalities during the neonatal period. ${ }^{24}$

Copyright@ 10 May, 2017.
REFERENCES

1. Ezechukwu CC, Ugochukwu EF, Egbuonu I, Chukwuka JO. Risk Factors for Neonatal Mortality in a Regional Tertiary Hospital in Nigeria. Niger J Clin Pract 2004; 7:50-5.

2. Lawn JE, Wilczynska-Ketende K, Cousens SN. Estimating the causes of $\mathbf{4}$ million neonatal deaths in the year 2000. Int J Epidemiol. 2006; 35(3):706-18.

3. Mathers CD, Boerma T, Fat DM. Global and Regional Causes of Death. Br Med Bull. 2009; 92:7-32.

4. Black RE, Cousens S, Johnson HL, Lawn C, Rudan I, Bassani DG, et al. Child Health Epidemiology Reference Group of WHO and UNICEF. Global, regional, and national causes of child mortality in 2008: a systematic analysis. Lancet. 2010; 375(9730): 1969-87.

5. Azam M, Khan PA, Malik FA. Birth Asphyxia: risk factors. The Professional 2004; 11(4):416-23.

6. Majeed R, Memon Y, Majeed F, Shaikh NP, Rajar UD. Risk factors of birth asphyxia. J Ayub Med Coll Abbottabad 2007; 19(3):67-71.

7. Jalil F. Perinatal health in Pakistan: a review of the current situation. Acta Pædiatr 2004; 93(10):1273-9.

8. Jehan I, Harris H, Salat S, Zeb A, Mobeen N, Pasha O, et al. Neonatal mortality, risk factors and causes: a prospective opulation-based cohort study in urban Pakistan. Bull World Health Organ 2009; 87(2):130-8.

9. Sepeku A, Kohi TW. Treatment Outcomes of Neonatal Asphyxia at a National Hospital In Dar Es Salaam, Tanzania. Afr J Nurs Midwifery 2011; 13(2):43-56.

10. Azzopardi DV, Strohm B, Edwards AD, Dyet L, Halliday $H L$, Juszczak E, et al. Moderate hypothermia to treat perinatal asphyxial encephalopathy. New Engl J Med 2009; 361(14):1349-58.

11. Gluckman PD, Wyatt JS, Azzopardi D, Ballard $R$, Edwards $A D$, Ferriero $D M$, et al. Selective head cooling with mild systemic hypothermia after neonatal encephalopathy: multicenter randomized trial. The Lancet 2005; 365(9460):663-70.

12. Marro PJ, Mishra OP, Delivoria-Papadopoulos $M$. Effect of allopurinol on brain adenosine levels during hypoxia in newborn piglets. Brain Res. 2006; 10734:444-50.

13. Bel FV, Shadid M, Moison RM, Dorrepaal CA, Fontijn J, Monteiro $L$, et al. Effect of allopurinol on postasphyxial free radical formation, cerebral hemodynamics, and electrical brain activity. Pediatrics 1998; $101(2) ; 185-93$. 
14. Van Bel F, Shadid M, Moison RM, Dorrepaal CA, Fontijn J, Monteiro $L$, et al. Effect of allopurinol on postasphyxial free radical formation, cerebral hemodynamics, and electrical brain activity. Pediatrics 1998; 101:185-93.

15. Bax MC, Flodmark O, Tydeman C. Definition and classification of cerebral palsy. From syndrome toward disease. Dev Med Child Neurol Suppl. 2007; 109:39-41.

16. Golubnitschaja O, Yeghiazaryan K, Cebioglu M, Morelli M, Herrera-Marschitz M. Birth asphyxia as the major complication in newborns: moving towards improved individual outcomes by prediction, targeted prevention and tailored medical care. EPMA Journal $2011 ; 2: 197-210$.

17. Butt TK, Farooqui R, Khan MA. Risk Factors for Hypoxic Ischemic Encephalopathy in Children. JCPSP 2008; 18(7):428-32.

18. Futrakul S, Praisuwanna P, Thaitumyanon P. Risk factors for hypoxic-ishemic encephalopathy in asphyxiated newborn infants. J Med Assoc Thai 2006; 89: 322-8.

19. Lee AC, Mullany LC, Tielsch JM, Katz J, Khatry
SK, LeClerq SC, et al. Risk factors for neonatal mortality due to birth asphyxia in southern Nepal: a prospective, community-based cohort study. Pediatrics. 2008; 121(5):e1381-90.

20. Silveira RC, Procianoy RS. Ischemic brain damage in very low birth weight preterm newborn infants. $J$ Pediatr 2005; 81 (1 suppl): S23-32.

21. Phillis JW, Lin Y. Oxypurinol reduces ischemic brain injury in the gerbil and rat. Adv Exp Med Biol. 1991; 309A:343-346.

22. Moorhouse PC, Grootveld M, Halliwell B, Quinlan JG, Gutteridge JMC. Allopurinol and oxypurinol are hydroxyl radical scavengers. FEBS Lett.1987; 21:238.

23. Gunes T, Ozturk MA, Koklu E, et al. Effect of allopurinol supplementation on nitric oxide levels in asphyxiated newborns. Pediatr Neurol 2007; 36:17-24.

24. Allopurinol for preventing mortality and morbidity in newborn infants with hypoxic-ischaemic encephalopathy. The Cochrane Library 2012; 7:1-21.

\section{PREVIOUS RELATED STUDY}

Muhammad Azam, Fiaz Ahmad Malik, Pervaiz Akbar. BIRTH ASPHYXIA; RISK FACTORS (Original) Prof Med Jour 11(4) 416-422 Oct, Nov, Dec, 2004.

\section{AUTHORSHIP AND CONTRIBUTION DECLARATION}

\begin{tabular}{|c|l|l|}
\hline Sr. \# & \multicolumn{1}{|c|}{ Author-s Full Name } & \multicolumn{1}{|c|}{$\begin{array}{c}\text { Contribution to the paper } \\
\text { Methodology, Design, Data } \\
\text { Analysis, Supervision } \\
\text { Drafting, Data Analysis }\end{array}$} \\
\hline 2 & Dr. Muhammad Amin & $\begin{array}{l}\text { Dr. Muhammad Saleem } \\
\text { Case selection, Discussion }\end{array}$ \\
4 & Dr. Shamas-un-Nisa & $\begin{array}{l}\text { Dr. Malik M. Naeem } \\
\text { Drafting, Data Analysis, } \\
\text { Literature Review, } \\
\text { References } \\
\text { Data Collection, Literature } \\
\text { Review, Drafting }\end{array}$ \\
\hline 5 & Dr. Hafiz M. Anwar-ul-Haq &
\end{tabular}

